\title{
A Comparative Study for Successful Treatment per Gender in a Specialized Smoking Cessation Unit in the Albacete University Hospital during Two Years
}

\author{
Francisco Javier Callejas González ${ }^{1}$, Genovés Crespo Marta ${ }^{2}$, Cruz Ruiz Javier ${ }^{1}$, Esquinas López Cristina ${ }^{3}$, \\ Tárraga López Pedro Juan ${ }^{4}$, Pablo Bermejo López ${ }^{5}$, Tornero Molina Ana Isabel ${ }^{1}$, Pastrana Calderón Juan ${ }^{1}$, Molina \\ Cano Angel ${ }^{1}$ and Rodríguez Montes José Antonio ${ }^{6}$ \\ 1 Pneumonology Department, The Albacete University Hospital Complex (CHUA), Albacete 02006, Spain \\ 2 Thoracic Surgery Department, The Albacete University Hospital Complex (CHUA), Albacete 02006, Spain \\ 3 Pneumonology Department, Vall d'Hebron University Hospital, Barcelona 08035, Spain \\ 4 Integrated Care Management, The Albacete University Hospital Complex (CHUA), Albacete 02006, Spain \\ 5 College of Computer Engineering, Castilla-La Mancha University (UCLM), Albacete 02071, Spain \\ 6 General and Digestive Surgery Department, La Paz University Hospital, Madrid 28046, Spain
}

Received: March 3, 2015 / Accepted: March 25, 2015 / Published: March 31, 2015.

\begin{abstract}
Objective: Analysis of abstinence rates of smokers per gender at 3, 6, 9 and 12 months in a Smoking Cessation Unit from January 2008 to December 2009. Methods: Descriptive retrospective study. Analysis of socio-demographic variables, smoking patterns, associated comorbidities, continuous abstinence rates, success, relapses, failure and dropping out. Results: 278 smokers started treatment (33\%); $55.4 \%$ males and $44.6 \%$ females (mean age of 48.3 and 44.06 years, respectively). The main associated comorbidities were: psychiatric (38.7\%), cardiovascular (dyslipemia 25\%) and respiratory (COPD (chronic obstructive pulmonary disease) $9.7 \%$ ) in females; cardiovascular (dyslipemia 34.4\%), psychiatric (34.4\%) and respiratory (COPD 19.5\%) in males. VRN (Varenicline) was prescribed in $40.2 \%$ males and $32.2 \%$ females; NRT (nicotine replacement therapy) was used in $46.6 \%$ and $38.7 \%$, respectively; bupropion was employed in $6.5 \%$ and $21.8 \%$, respectively. Psychological counseling was offered only to $7.8 \%$ males and $8.1 \%$ females. The continuous abstinence rates in males at 3, 6, 9 and 12 months were $51.3 \%, 37.7 \%, 32.5 \%$ and $30.5 \%$, respectively, and were $45.2 \%$, $29.8 \%, 25.0 \%$ and $24.2 \%$ for females. Failure was $9.7 \%$ for females and $18.8 \%$ for males. Success was more frequent for those on VRN ( $n=41$ males; $n=12$ females). No relapses were indicated for 42 females and 71 males. The percentage of relapses was higher at 3 months $(29.0 \%$ females, $19.5 \%$ males). Conclusions: The study observed differences in treating abstinence between genders (in the abstinence rates and failure index). This implies having to consider incorporating the gender variable into the diagnosis, treatment and prevention of smoking.
\end{abstract}

Key words: Smoking, smoking cessation, gender, continuous abstinence, successful treatment, failure, relapse.

\section{Introduction}

Smoking is defined as a chronic addictive and relapsing disease due to the dependence that nicotine causes, and is the first cause of avoidable morbid-mortality worldwide. In the authors' setting,

Corresponding author: Francisco Javier Callejas González, M.D., Ph.D., research fields: respiratory medicine, tobacco cessation, COPD and asthma. E-mail: f.javiercallejas@hotmail.com. one in every seven deaths of people aged over 35 is secondary to smoking. There are significant differences between genders: in males, smoking is the cause of 1 death in every 4 , but it is much lower in females (1 in every 29) [1-3]. However, these differences have reduced in recent years.

The WHO states that "quitting smoking is the most efficient and important public health measure that 

the Albacete University Hospital during two years

countries can take to help benefit the health of their citizens and their economy". For all these reasons, smoking cessation units have been set up in Spain. These centers are willing to perform healthcare, teaching and research activities on aspects related to preventing, diagnosing and treating smoking [4].

The objective of the study was to analyze the study sample in the Smoking Cessation Unit of Albacete and to observe if there were any differences between both genders as far as the socio-demographic variables are concerned (smoking pattern, abstinence rates, success, relapses, failure and dropping out) despite the major limitations that appear in a retrospective study of this kind.

\section{Materials and Methods}

A retrospective and descriptive study of the results obtained after analyzing the sample of patients, and comparing the males and females, who came to the Smoking Cessation Unit of the Albacete University Hospital Complex between January 1, 2008 and December 31, 2009.

Patients' follow-up comprised a first visit when a general clinical history and a specific clinical history of smoking were created (current smoking habit, age when they started smoking, number of times they previously stopped smoking). During a physical examination, CO-oximetry was measured, and Fagerström and Richmond tests were done. Finally, a date for smoking cessation was set and a decision was made on pharmacological treatment based on the variables collected in case histories and patient preferences as far as possible. During successive visits, days of abstinence were recorded, withdrawal syndrome was evaluated, and response to treatment and its side effects were noted, all combined with support therapy and strategies to prevent relapses.

The main parameter used to measure treatment efficacy was the continuous abstinence rate after 1 year, defined as successful treatment. Treatment was considered a success for those patients who showed continuous abstinence since the set date to quit smoking, day, to 12 months without smoking. Other continuous smoking cessation cut-off points were used: 3, 6 and 9 months after smoking cessation treatment began. Validation of abstinence was verified by CO-oximetry and the patient's verbal statement in all cases. Conversely, treatment was considered to fail when patients presented less than $24 \mathrm{~h}$ of continuous abstinence. Values were measured with a Micro Smokerlyzer CO-oximeter (Bedfont Scientific; Rochester, UK) by fixing $\mathrm{CO}$ concentrations in exhaled air to be under $10 \mathrm{ppm}$. Patients were treated with the psychological and pharmacological combination, using $300 \mathrm{mg}$ bupropion, $1 \mathrm{mg}$ or $0.5 \mathrm{mg}$ VRN every $12 \mathrm{~h}$ and/or NRT as $21 \mathrm{mg}, 14 \mathrm{mg}$ and $7 \mathrm{mg}$ chewing gum, pills and/or patches.

The study variables were obtained by means of a clinical interview, doing a clinical history review and using a database created with the SPSS software, version 18. First a data quality control was carried out by identifying any anomalous data in each variable. Then the frequency and valid percentage of the qualitative variables were determined, while central trend measures (mean), dispersion measures (interquartile range-IQR) were employed with the quantitative variables.

\section{Results}

\subsection{Sample Description}

From January 1, 2008 to December 31, 2009, 838 patients were referred to the authors' unit, of whom 559 actually came $(66.7 \%) ; 53.7 \%(\mathrm{n}=300)$ were males and $46.3 \%(n=259)$ were females. Two hundred and eighty-one smokers did not return after the first visit, which left 278 smokers who started treatment $(33 \%)$. Of these $278,55.4 \%$ were males $(\mathrm{n}=154)$ and $44.6 \%$ were females $(n=124)$, and their mean age was 48.30 and 44.06 years, respectively (Table 1 ).

The mean age at which smoking commenced was 17.5 years in females and 16.2 years in males (with an age range of 8-36 years in males and 12-36 years in 
Table 1 Smoking cessation without starting treatment per gender ( $\% \mathrm{y}$ frequency).

\begin{tabular}{|c|c|c|c|c|c|c|}
\hline \multicolumn{7}{|c|}{ Smoking cessation without starting treatment } \\
\hline Gender & & & Frequency & Percentage & $\%$ valid & $\%$ accumulated \\
\hline \multirow{3}{*}{ Males } & \multirow{3}{*}{ Valid } & No & 154 & 51.3 & 51.3 & 51.3 \\
\hline & & Yes & 146 & 48.7 & 48.7 & 100.0 \\
\hline & & Total & 300 & 100.0 & $100 / 0$ & \\
\hline \multirow{3}{*}{ Females } & \multirow{3}{*}{ Valid } & No & 124 & 47.9 & 47.9 & 47.9 \\
\hline & & Yes & 135 & 52.1 & 52.1 & 100.0 \\
\hline & & Total & 259 & 100.0 & 100.0 & \\
\hline
\end{tabular}

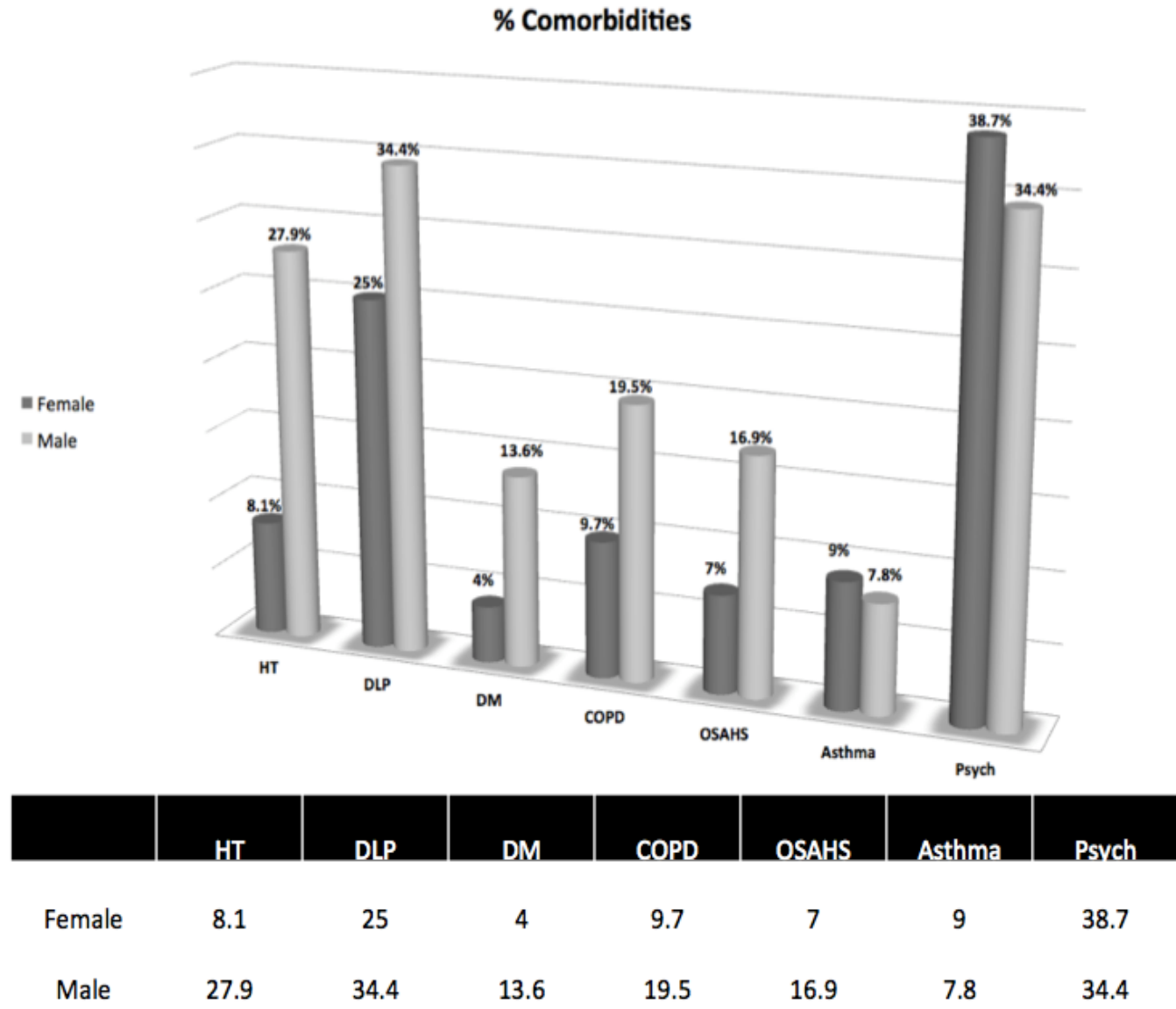

Fig. 1 Comorbidities associated by gender.

HT: Hypertension; DLP: Dyslipidemia; DM: Diabetes Mellitus; COPD: Chronic Obstructive Pulmonary Disease; OSAHS: Obstructive Sleep Apnea-Hypoapnea Syndrome; Psych: Psychiatric Comorbidity.

females), and the mean number of cigarettes smoked was 23.7 and 30.3 cigarettes per day (cig/day), respectively. Mean physical dependence, measured by the Fagerström test, was 6.19 in females and 6.09 in males. According to the Richmond test, this is the equivalent to a moderate-severe degree, and to a high degree of motivation with a mean value of 8.21 in females and 8.35 in males. The concentrations determined by Co-oximetry gave a mean value of 16.30 in females, with a standard deviation of 8.86, and of 17.24 in males with a standard deviation of 10.36 .

Fig. 1, the associated comorbidities, mainly in females, were psychiatric (38.7\%), cardiovascular (dyslipemia-DLP, 25\%, high blood pressure-HT, 8.1\% and diabetes-DM, 4\%) and respiratory (COPD, 9.7\%, Obstructive Sleep Apnea-Hipopnea Syndrome-OSAHS, 

the Albacete University Hospital during two years

$7 \%$ and asthma, 9\%) pathologies. In males, they were cardiovascular (DLP, 34.4\%, HT, 27.9\% and DM, $13.6 \%)$, psychiatric $(34.4 \%)$ and respiratory (COPD, 19.5\%, OSAHS, 16-9\% and asthma, 7.8\%) pathologies.

\subsection{Treatment Protocols}

Of all the patients in the study, $100 \%$ received personalized treatment with pharmacological therapy and/or psychotherapy. In the authors' sample, NRT was prescribed to $46.45 \%$ of treated males and to $37.9 \%$ of females, VRN was prescribed to $38.96 \%$ of males and to $31.45 \%$ of females, while the VRN + NRT treatment combination was used only in $1.29 \%$ of males and $0.8 \%$ of females. Finally, BPN (bupropion) was prescribed to $6.5 \%$ of males and to $22.2 \%$ of females. Psychotherapy without pharmacological treatment was carried out in $7.8 \%$ of male smokers and in $8.1 \%$ of smoking females.

\subsection{Successful Treatment}

The frequencies and percentages of the abstinence rates at 3, 6, 9 and 12 months were collected (see Table 2 and Fig. 2). Of the 154 treated males, successful treatment at 12 months was $30.5 \%(n=47)$, as this table shows, and was $24.2 \%$ for 124 women $(n=30)$.

Table 3 indicates the success of each prescribed drug,

Table 2 Continuous abstinence rates at 3, 6, 9 and 12 months at the SSCU (Specialized Smoking Cessation Unit) at the Albacete University Hospital Complex according to gender.

\begin{tabular}{|c|c|c|c|c|c|c|}
\hline \multicolumn{7}{|c|}{ Continuous abstinence rates at 3 months } \\
\hline Sex & & & Frequency & Percentage & $\%$ valid & $\%$ accumulated \\
\hline \multirow{3}{*}{ Males } & \multirow{3}{*}{ Valid } & No & 75 & 48.7 & 48.7 & 48.7 \\
\hline & & Yes & 79 & 51.3 & 51.3 & 100.0 \\
\hline & & Total & 154 & 100.0 & 100.0 & \\
\hline \multirow{3}{*}{ Females } & \multirow{3}{*}{ Valid } & No & 68 & 54.8 & 54.8 & 54.8 \\
\hline & & Yes & 56 & 45.2 & 45.2 & 100.0 \\
\hline & & Total & 124 & 100.0 & 100.0 & \\
\hline \multicolumn{7}{|c|}{ Continuous abstinence rates at 6 months } \\
\hline \multirow[t]{2}{*}{ Sex } & & & Frequency & Percentage & $\%$ valid & $\%$ accumulated \\
\hline & & No & 96 & 62.3 & 62.3 & 62.3 \\
\hline \multirow[t]{3}{*}{ Males } & Valid & Yes & 58 & 37.7 & 37.7 & 100.0 \\
\hline & & Total & 154 & 100.0 & 100.0 & \\
\hline & & No & 87 & 70.2 & 70.2 & 70.2 \\
\hline \multirow[t]{2}{*}{ Females } & Valid & Yes & 37 & 29.8 & 29.8 & 100.0 \\
\hline & & Total & 124 & 100.0 & 100.0 & \\
\hline \multicolumn{7}{|c|}{ Continuous abstinence rates at 9 months } \\
\hline \multirow[t]{2}{*}{ Sex } & & & Frequency & Percentage & $\%$ valid & $\%$ accumulated \\
\hline & & No & 104 & 67.5 & 67.5 & 67.5 \\
\hline \multirow[t]{3}{*}{ Males } & Valid & Yes & 50 & 32.5 & 32.5 & 100.0 \\
\hline & & Total & 154 & 100.0 & 100.0 & \\
\hline & & No & 93 & 75.0 & 75.0 & 75.0 \\
\hline \multirow[t]{2}{*}{ Females } & Valid & Yes & 31 & 25.0 & 25.0 & 100.0 \\
\hline & & Total & 124 & 100.0 & 100.0 & \\
\hline \multicolumn{7}{|c|}{ Continuous abstinence rates at 12 months } \\
\hline \multirow[t]{2}{*}{ Sex } & & & Frequency & Percentage & $\%$ valid & $\%$ accumulated \\
\hline & & No & 107 & 69.5 & 69.5 & 69.5 \\
\hline \multirow[t]{3}{*}{ Males } & Valid & Sí & 47 & 30.5 & 30.5 & 100.0 \\
\hline & & Total & 154 & 100.0 & 100.0 & \\
\hline & & No & 94 & 75.8 & 75.8 & 75.8 \\
\hline \multirow[t]{2}{*}{ Females } & Valid & Sí & 30 & 24.2 & 24.2 & 100.0 \\
\hline & & Total & 124 & 100.0 & 100.0 & \\
\hline
\end{tabular}




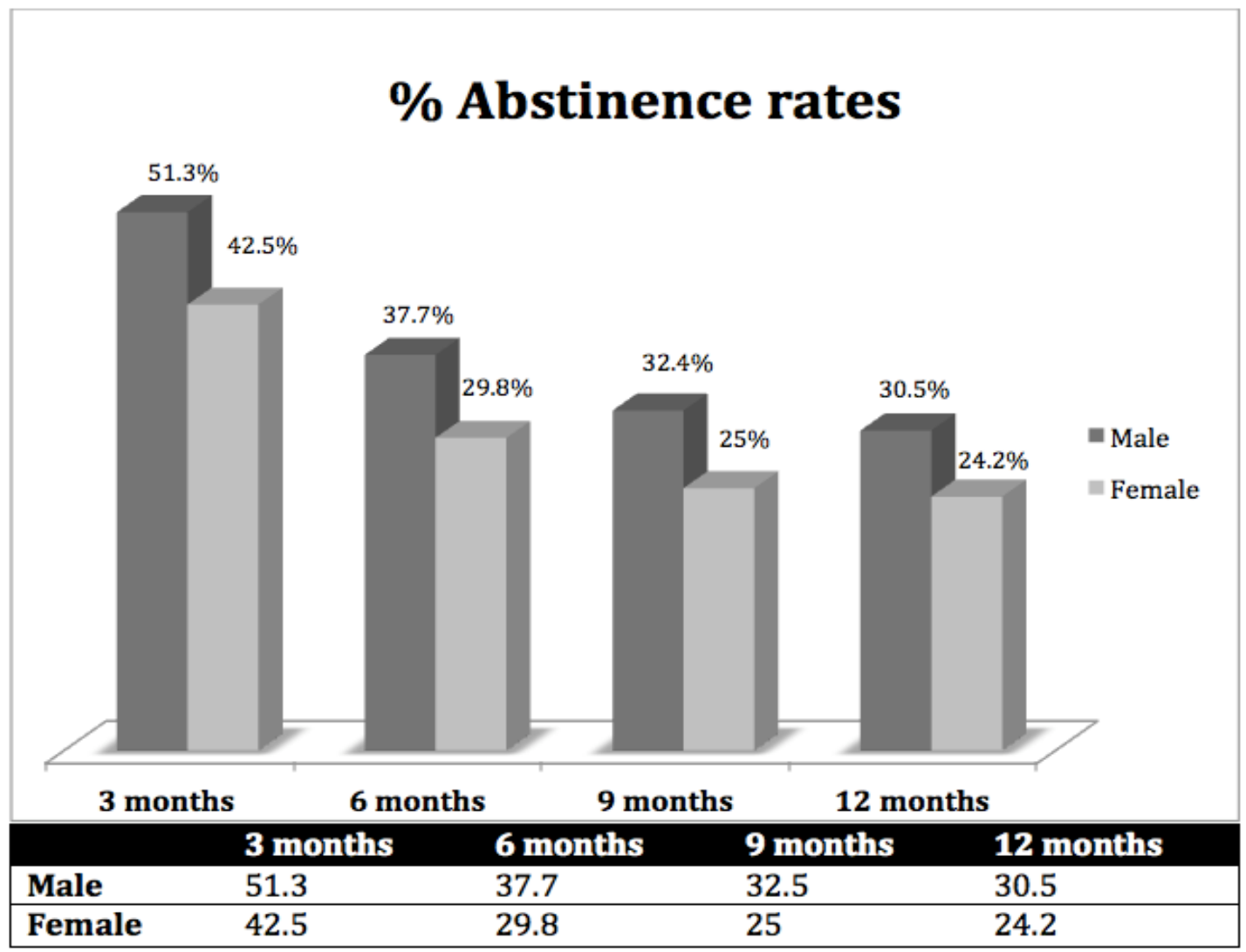

Fig. 2 Comparative figure of continuous abstinence rates at 3, 6, 9 and 12 months according to gender.

according to gender, for all the patients who started treatment. Fig. 3 illustrates the prescribed treatment in the males and females who achieved continuous abstinence at 12 months (success).

\subsection{Relapses, Failure and Dropping out}

Of the 154 treated males, 71 did not relapse, nor did 42 of the 124 females. The third month was when more relapses occurred in males (19.5\%) and females (29\%). Treatment failed for $9.7 \%$ of smoking females, and this percentage was higher in males $(18.8 \%)$. The most frequent reason for dropping out was the patient's own decision in both genders (females $=27$, males $=50$ ).

\section{Discussion}

Over the years in all nationwide health surveys, and also in the data collected in CLM (Castilla-La Mancha), the geographic region, and in the study sample, males smoked more than females. When comparing differences in smoking in 2006 between both genders, the figures in CLM were higher than in Spain as a whole: $34.07 \%$ of males and $19.85 \%$ of females in CLM as opposed to $31.6 \%$ of males and $21.51 \% 5$ of females in Spain. In the authors' sample, differences in smoking were smaller with $55.4 \%$ in males and $44.6 \%$ in females. The authors considered this to be logical as the studied unit was where heavy smokers and those who had previously attempted to quit smoking were referred to.

Differences in the profile of the males and females included in the study for smoking patterns, as the literature has already described, were fewer cig/day and a lower degree of nicotine dependence among females, whereas males tended to have smoked more years [6]. The authors' results are similar to those reported in other studies, and they found no difference 
in degree of physical dependence. This can be justified by the type of patients who come to the Smoking Cessation Unit, who are heavy smokers and present a considerable degree of physical dependence [7, 8]. In the present study, females smoked less cig/day than males (23.7 cig/day vs. $30.3 \mathrm{cig} /$ day, respectively).
A comparative study would be necessary to know if the daily smoking of the females referred to the authors' unit increased or decreased in recent years. However it is noteworthy that the percentage of cigarettes per day shown in this group came close to that of males.

Table 3 Success in males and females according to the prescribed drug of all the patients who started treatment.

\begin{tabular}{llll}
\hline MALES & & & Total \\
\hline Treatment & Unsuccessful & Successful & 12 \\
Psychotherapy & 5 & 7 & 60 \\
VRN & 40 & 20 & 70 \\
TSN & 53 & 17 & 2 \\
VRN + NRT & 1 & 1 & 10 \\
BPN & 8 & 2 & 154 \\
\hline FEMALES & 107 & 47 & Total \\
Treatment & & & 10 \\
Psychotherapy & Unsuccessful & Successful & 39 \\
VRN & 9 & 1 & 47 \\
TSN & 27 & 12 & 1 \\
VRN + NRT & 36 & 11 & 27 \\
BPN & 1 & 0 & 124 \\
\hline NRT: Nictin & 21 & 6 & The
\end{tabular}

NRT: Nicotine Replacement Therapy; VRN: Varenicline; VRN + TSN: Varenicline + Nicotine Replacement Therapy, BPN: Bupropion

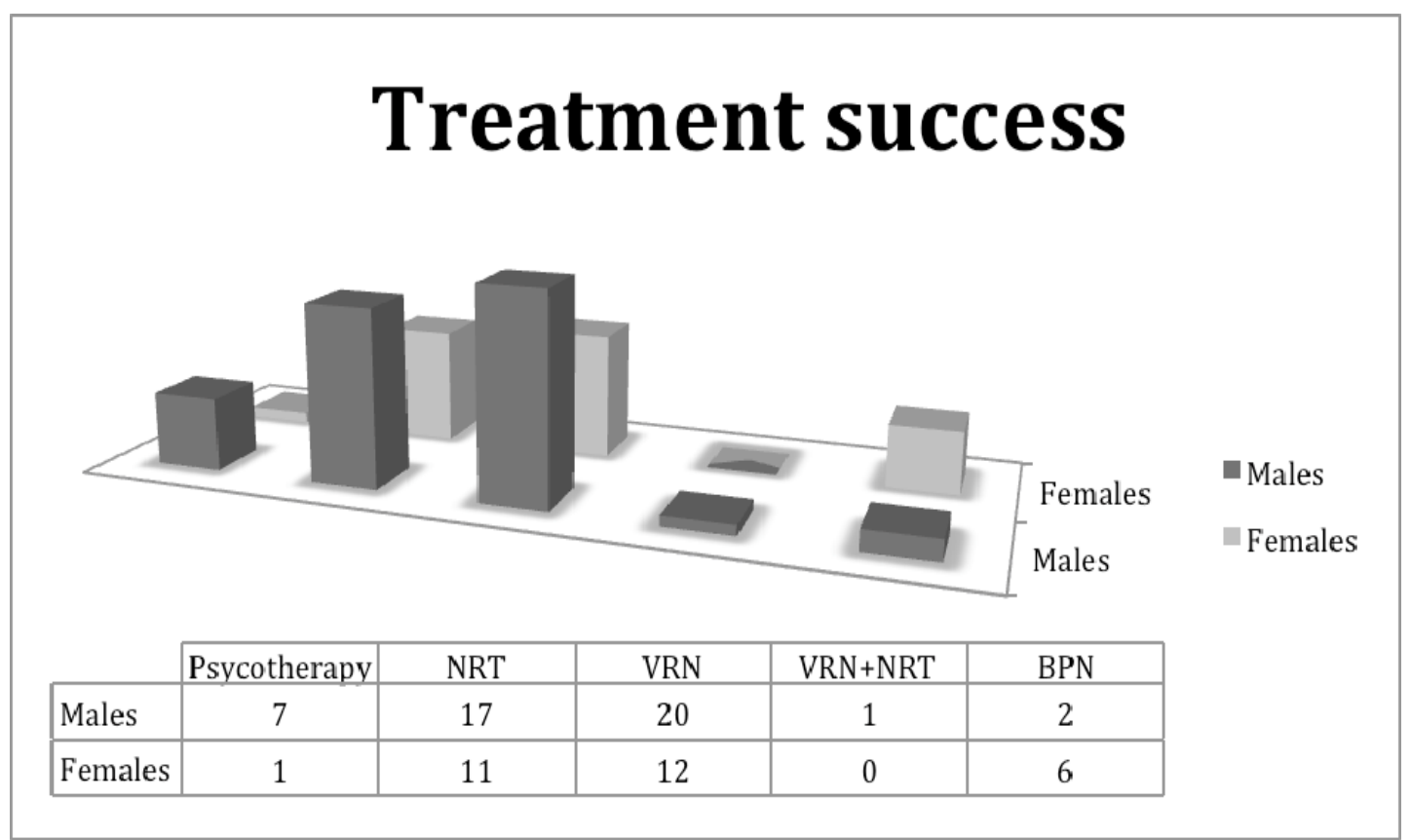

Fig. 3 Success in males and females of the various treatments prescribed and who achieved continuous abstinence rates at 12 months.

NRT: Nicotine Replacement Therapy; VRN: Varenicline; VRN + TSN: Varenicline + Nicotine Replacement Therapy; BPN: Bupropion 
The most important comorbidities were psychiatric, respiratory and cardiovascular risk factors. In general terms, comorbidity was slightly higher in the group of males in nearly all the sections, except that referring to a psychiatric background, where incidence was higher among females (38.7\% vs. 34.4\%), which also applied to other smoking units.

These data coincide with those found for the general population [5] and also with those described in the literature. What this reveals is that these problems appear more frequently in females, irrespectively of them being smokers [9] or non smokers [5]. It is worth mentioning the relationship between smoking and psychiatric comorbidity. Since 1986, the scientific community began to corroborate a close association between smoking and presence of psychiatric symptoms [10, 11]. Smoking is more prevalent in almost every type of psychiatric pathology, and the likelihood of a person who smokes having a mental disorder more or less doubles that of someone with no such a disorder [10-12]. In general, there is a directly proportional relationship between intensity of clinical psychiatrics and severity of depending on smoking [13]. Among the co-morbid conditions associated with smoking, the authors encounter state of mind disorders (depression and bipolar disorder), psychotic disorders (schizophrenia), alcoholism and other drug addictions, anxiety disorders, eating disorders, and a background of attention deficit disorders [14].

As previously mentioned, the treatment any smoker must receive includes a combination of pharmacological treatment and psychological counseling. Psychological treatment intends to amend a smoker's conduct in order to channel, replace and suppress the smoking impulse acquired. Of all the psychological techniques used to treat smoking cessation, the cognitive behavioral therapy stands out [15], which is what the authors use in their consultations.

Psychological therapy to treat smoking can be basically carried out in two ways: individually and as group therapy [15]. In their sample, all the patients received individual treatment, and the psychological cognitive behavioral therapy was used in them all. All the published meta-analyses coincide in pointing out that smoking treatment efficacy is independent of the format it is offered in [16-18]. The indication of one format or another depends on the characteristics of the population being attended to and the therapeutic team's working methodology. According to the characteristics of the consultation, space and personnel, their group used only an individual format.

In any case, pharmacological treatment to quit smoking is indicated for any smoker who is willing to make a serious attempt to do this, and healthcare professionals should suitably follow them up. It is well-known that when smokers seriously attempt to give up smoking and do not receive adequate treatment, their chances of success are barely $5-10 \%$. Conversely if they receive suitable treatment, their chances of success multiply by three [16]. So it is compulsory to acquire suitable treatment protocols for all smokers willing to seriously leave the habit. Pharmacological treatment is particularly suitable for patients with a higher degree of nicotine dependence.

The frontline drugs to pharmacologically treat smoking cessation that are available in Spain are NRT, BPN and VRN. Prescribing one of these drugs in this study depended on patients' clinical characteristics, degree and severity of smoking, and each smoker's personal preferences[16, 19]. The SEPAR guidelines for dose and duration of prescribed pharmacological treatments were always followed $[17,19]$.

NRT is defined as administering nicotine to a smoker who seriously wishes to quit smoking, but in a different way to cigarettes (in Spain, NRT is available as gum, pills and skin patches) in an amount that is sufficient $(5-15 \mathrm{ng} / \mathrm{mL})$ to avoid unpleasant nicotine abstinence syndrome effects, but one that avoids creating dependence $[20,21]$. In the authors' study sample, NRT was the most widely prescribed treatment (46.45\% in males and $37.9 \%$ in females). Its 

the Albacete University Hospital during two years

success rate was $24.28 \%$ in males and $23.40 \%$ in females.

The combination of several NRT forms is indicated for some patients. Unfortunately however, there are no exact indications available to set up combined therapy. Nonetheless, this possibility should be considered in smokers who smoke more than 30 packets/year, who score 7 or more in the Fagerström test, and obtain a CO-oximetry result above $30 \mathrm{ppm}$, and/or for those smokers who have used simple therapies in previous attempts, and have relapsed from suffering abstinence syndrome effects. In the authors' sample, three smokers ( 2 males, 1 female) met one of these criteria, and were prescribed the NRT + VRN combination.

Bupropion [16, 22] is an atypical antidepressant drug that belongs to the group of second-generation antidepressant drugs that come as 150-mg hydrochloride bupropion pills covered with extended-release film. In our sample, $6.5 \%$ of males and $21.7 \%$ of females received bupropion treatment, and their success rate was $20.0 \%$ and $22.2 \%$, respectively.

Varenicline was the first non-nicotine drug to have been specifically developed for smoking cessation. It acts as a partial nicotine agonist that selectively acts on $\alpha 4 \beta 2$ receptors to give rise to higher dopamine levels, which avoids abstinence syndrome manifestations and, as it occupies the receptors that compete with nicotine, it simultaneously avoids nicotine acting on the CNS. It also avoids the pleasant effects of nicotine acting on the mesolimbic system of the CNS. In the study, 38.96\% and $31.45 \%$ of smoking males and females, respectively, started treatment with VRN. Their success rate was $33.33 \%$ and $30.76 \%$, respectively. The VRN + NRT combination was used to treat two males and one female of the authors' sample. Of these, only one male succeeded, and the other male and the female did not achieve 12-month continuous abstinence.

In short, NRT was the most widely used therapy, regardless of it being used as gum, patches or being combined with VRN, followed by VRN, and finally by BPN. The highest success rate was obtained for VRN in both genders.

The authors ought to bear in mind the possibility of a bias when selecting patients for treatment groups when it comes to deciding with a doctor some treatments to be received because this could mean that it would depend on several patient factors. This would produce dependence and a correlation between factors and treatments, which could invalidate the statistical inference relating to the results for the effect of treatments. So it is necessary to first consider that the objective of this study was to analyze the factors that could be related with the results obtained for abstinence rates after a follow-up period.

Based on the results of treating smoking, several studies have contemplated the existence of differences between males and females. They found that smoking cessation rates in females were consistently lower than in males [23, 24], which was also demonstrated in our study $(30.5 \%$ of males were successful vs. $24.2 \%$ of females).

Basically, if the authors bear in mind the major differences among them in terms of design and ways of acting, in comparison to the results of these units, the results of the Albacete unit were not that different since the overall continuous abstinence rates obtained in males were $51.3 \%$ at 3 months, $37.7 \%$ at 6 months, $32.5 \%$ at 9 months and $30.5 \%$ at 12 months, and were $45.2 \%, 29.8 \%, 25.0 \%$ and $24.2 \%$ in females, respectively (see Table 2). These results confirm that, as previously stated [23, 24], the cessation rates in females are consistently lower than in males.

One limitation of the study, as in other similar studies, is that the authors' sample was not representative of the smoking population as it was made up of patients who asked to be referred to the authors' unit either through their own decision or because other healthcare professionals sent them. In any case, the authors believe that their sample was large enough to attempt to analyze the differences 


\section{A Comparative Study for Successful Treatment per Gender in a Specialized Smoking Cessation Unit in the Albacete University Hospital during two years}

between genders without straying from the initial objective.

By way of conclusion, the profiles of both the males and females who started smoking cessation treatment differed. Hence the authors' should consider adding the gender perspective to approach the diagnosis, therapy and prevention of smoking as a disease.

\section{What is known on the subject?}

There are numerous studies that have analyzed predictor factors of successful smoking cessation, and one of the most frequently repeated ones is gender. However, the results are contradictory and not altogether conclusive. Nowadays, there are not many research works on the appearance of differences or not according to gender, which encouraged us to carry out this project.

\section{What does the study add to the literature?}

The work intended to go more deeply into differences between genders in smoking cessation to be able to draw conclusions so the authors will be able to advance in treating their patients' smoking. Hence the authors' believe that it is necessary to include the gender perspective in the usual management of these patients.

\section{References}

[1] The World Health Organization. 1992. The ICD-10 Classification of Mental and Behavioural Disorders: Clinical Descriptions and Diagnostic Guidelines. Geneva: World Health Organization.

[2] WHO. International Classification of Diseases (ICD). Available at: http: //www.who.int/ classifications/ icd/en/index.html\#. [Consulted on 07/12/2011].

[3] De Granda Orive JI. El tabaquismo como enfermedad adictiva crónica. En: Jiménez-Ruiz CA y Fagerström KO (Ed). Tratado de Tabaquismo. 2nd Edition. Madrid. Ergon. 2007. pp. 99-119.

[4] Http://www.separ.es/areas/tabaquismo/justificacion

[5] Ministerio de Sanidad y Consumo. Instituto Nacional de Estadística. Encuesta Nacional de Salud de España años 1987, 1993, 1995, 1997, 2001, 2003 y 2006. Madrid.

[6] Gritz, E. R., Thompson, B., and Emmons, K. 1998. "Gender Differences among Smokers and Quitters in the Working Well Trial." Prev Med. 27: 553-61.

[7] Fernández, E., Schiaffino, A., and Borrell, C. 2006.
"Social Class, Education, and Smoking Cessation: Long-Term Follow-up of Patients Treated at a Smoking Cessation Unit." Nic Tob Res. 8: 29-36.

[8] Barrueco, M., Torrecilla, M., Maderuelo, J. A., Jiménez, R. C., Hernández, M. A., and Plaza, M. D. 2001. "Valor Predictivo de la Abstinencia tabáQuica a los 2 Meses de Tratamiento." Med. Clin. 116: 246-50.

[9] Croghan, I. T., Ebbert, J. O., and Hurt, R. D. 2009. "Gender Differences among Smokers Receiving Interventions for Tobacco Dependence in A Medical Setting." Addict Behav. 34: 61-7.

[10] McNeill, A. 2001. Smoking and Mental Health: A Review of the Literature. London: Action on Smoking and Health.

[11] Brown, C. 2004. Tobacco and Mental Health: A Review of the Literature. ASH Scotland, Edinburgh.

[12] Lasser, K., Boyd, W., and Woolhandler, S. 2000. "Smoking and Mental Illness: A Population-Based Prevalence Study." JAMA 284: 2606-10.

[13] Coney, J. L., Stevens, T. A., and Conney, N. L. 1998. "Comorbidity of Nicotine Dependence with Psychiatric and Substance-Use Disorders." In Dual Diagnosis and Treatment, edited by Kranzler, H. R., and Rousanville, B. J. New York: Marcel Dekker.

[14] Sung, H. Y., Prochaska, J. J., Ong, M. K., Shi, Y., and Max, W. 2011. "Cigarette Smoking and Serious Psychological Distress: A Population-Based Study of California Adults." Nic. Tob. Res. 13 (12): 1183-92.

[15] Becoña Iglesias E. Módulo 8: Tratamiento I. Unidad 3. Tratamiento psicológico. Intervenciones individuales y grupales. En: Máster en Prevención y Tratamiento del Tabaquismo. Instituto for Lifelong Learning. Universitat de Barcelona. UB virtual edition. 2008.

[16] Fiore, M. C., Jaén, C. R., Baker, T. B., Bailey, W. C., Benowitz, N., and Curry, S. Treating Tobacco use and dependence: 2008 update. Clinical practice guideline, Rockville MD: US. Deparment of Health and Human Service. May 2008. Translation into Spanish: Guía de Tratamiento del Tabaquismo. Jiménez-Ruiz CA, Jaén CR (coordinadores de la traducción). Sociedad Española de Neumología y Cirugía Torácica. SEPAR; May 2010.

[17] Jiménez-Ruiz, C. A., de Granda Orive, JI., Solano Reina, S., Carrion, F., Romero Palacios, P., Barrueco Ferrero, M., Recomendaciones para el tratamiento del tabaquismo. Arch Bronconeumol 2003; 39: 514-23.

[18] Stead, L. F., and Lancaster, T. 2005. "Group Behavior Therapy Programs for Smoking Cessation." Cochrane Database Syst. Rev. 18 (2): CD001007.

[19] Jiménez-Ruiz, C. A., Riesco Miranda, JA., Ramos Pinedo, A., Barrueco Ferrero, M., Solano Reina, S., de Granda Orive, JI., et al. Recomendaciones para el tratamiento farmacológico del tabaquismo. Propuesta de financiación. Arch Bronconeumol 2008; 44:213-9. 
112 A Comparative Study for Successful Treatment per Gender in a Specialized Smoking Cessation Unit in the Albacete University Hospital during two years

[20] Ruíz Martín, J. J., Jiménez-Ruiz, C. A., Solano Reina, S., Módulo 8: Tratamiento I. Unidad 6. Terapia sustitutiva con nicotina. En: Máster en Prevención y Tratamiento del Tabaquismo. Instituto for Lifelong Learning. Universitat de Barcelona. UB virtual edition. 2008.

[21] Jiménez-Ruiz, C. A., Solano Reina, S., González de Vega, J. M., Ruiz Pardo, M., Flórez Martín, S., Ramos Pinedo, A., y cols. Normativa para el tratamiento del tabaquismo. Arch Bronconeumol 1999; 335: 499-506.

[22] Rodríguez Hermosa, J. L., Calle Rubio, M., Álvarez-Sala Walther, J. L., Módulo 8: Tratamiento I. Unidad 7. Bupropión. En: Máster en Prevención y Tratamiento del Tabaquismo. Instituto for Lifelong Learning. Universitat de Barcelona. UB virtual edition. 2008.

[23] Epperson, C. N., Toll, B., Wu, R., Amin, Z., Czarkowski, K. A., Jatlow, P., Mazure, C. M., and O'Malley, S. S. 2010. "Exploring the Impact of Gender and Reproductive Status on Outcomes in Randomized Clinical Trial of Naltrexone Augmentation of Nicotine Patch.” Drug Alcohol Depend 2010; 1:112(1-2):1-8. Epub 2010 Jun 19.

[24] Piper, M. E., Cook, J. W., Schlam, T. R., Jorenby, D. E., Smith, S. S., Bolt, D. M., and Loh, W. Y. 2010. "Gender, Race, and Education Differences in Abstinence Rates among Participants in Two Randomized Smoking Cessation Trials." Nic. Tob. Res. 12 (6): 647-57. 